\title{
Design of a benchmark test artifact to investigate 316 L stainless steel print quality and properties
}

\author{
Lucas Gallant*, Amy Hsiao, Grant McSorley \\ Faculty of Sustainable Design Engineering, University of Prince Edward Island, Charlottetown, Canada \\ *lggallant@upei.ca
}

\begin{abstract}
Additive manufacturing (AM) has become a popular fabrication technique with continual increasing development for hobbyists, industrial applications, and ongoing research. With the development of metal-based AM processes, the quality of built parts in terms of dimensional accuracy and material properties must be investigated to better understand the effect of printer process parameters and how performance can be controlled for desired part characteristics. This paper summarizes the previous existing designs and documented key aspects and considerations for test artifacts upon which a new test artifact was designed for use on analyzing builds of two 3D metal printers. The artifact designed includes features for dimensional analysis as well as novel features for strength and other material properties. Initial prints of $316 \mathrm{~L}$ stainless steel show geometric accuracies of -0.35 to $0.09 \mathrm{~mm}$ and -0.45 to $0.15 \mathrm{~mm}$ and reasonable values for surface roughness, hardness, and strength. Indications of anisotropy were found through strength and hardness testing, which will be further investigated moving forward to record the effect of process parameters on the properties.
\end{abstract}

Keywords-DMLS; test artifact; benchmark; additive manufacturing; mechanical properties; accuracy

\section{INTRODUCTION}

The use of direct metal laser sintering (DMLS) is becoming well established in many manufacturing sectors, especially aerospace for the increased life cycle and weight reduction capabilities [1]. Despite the acceptance of Additive Manufacturing (AM), its widespread implementation is inhibited by issues with part accuracies, surface properties, and control and characterization of mechanical properties [2]. There remains a lack of standards for AM, including DMLS prints; therefore, benchmark specimens are used to gain information about specific machine abilities and print quality characteristics [3]. These artifacts allow for the investigation of specific print characteristics, for example, surface roughness, dimensional errors, material properties, and feature limitations $[1,4,5]$. This paper focuses on the development of a benchmark test artifact that contains many features for dimensional analysis, mechanical properties, thermal properties, surface properties, etc. The specimen is designed in consideration of the build volume and properties of the EOS M100 and is used to compare and relate the performance and characteristics of $316 \mathrm{~L}$ stainless steel prints completed on an EOS M100 and M290 printer and identify notable properties to study further.

\section{BENCHMARKING}

\section{A. Design of a Test Specimen}

In defining the intent of the proposed test artifact for NIST, Moylan [2] constructed a generalized list of eight key print criteria to test in an AM test artifact for the assessment of a machine or process. They suggested an AM process should be capable of printing:

- $\quad$ straight features,

- parallel and perpendicular features,

- circular and arced features,

- fine features of minimum attainable size,

- freeform features,

- holes and bosses,

- $\quad$ in the horizontal and vertical plane, and

- features in the correct locations and orientation

Other 'rules' have also been established to consider when designing an ideal test part, which are not included in the eight criteria. The qualities noted by Ritcher and Jacobs [6] included that the test artifact be large enough so the edges and center of the build area are tested, that it should have a variety of sized features, that the print time is minimized, that minimal material is used, that the features should be easy to measure, and that the part contains many features found in functional parts. Scarvetti [7] added that to determine the source of defects, a test artifact should be made of simple shapes for defining geometry, allow for repeatability measurements, and require no manual intervention or support material.

There have been several widely referenced benchmark parts in the past that follow the above rules to varying extents and are applicable to DMLS printing [1, 2, 8, 9]. Kruth [8] 
presented an artifact that included flat surfaces for surface roughness measurements as well as small holes, small cylinders, and thin walls for dimensional analysis (Fig. 1). Other features of the design included sharp corners for investigating overheating, a sloping plane for investigating the stair effect of layers, and a thin plane to indicate warping. The artifact also allowed for pieces to be cut out for mechanical testing. A test specimen used by Castillo [9] (Fig. 2) included a feature of multiple planes at different angles, tall extrudes, and a hemisphere. For their comparison of prints from different machine vendors, Yasa [1] developed a modified version of Kruth's design by incorporating angle specimens similar to Castillo as well as a pipe extrusion (Fig. 3). Moylan [2] put forth a proposal for a standard specimen in compliance with the eight previously mentioned criteria (Fig. 4).

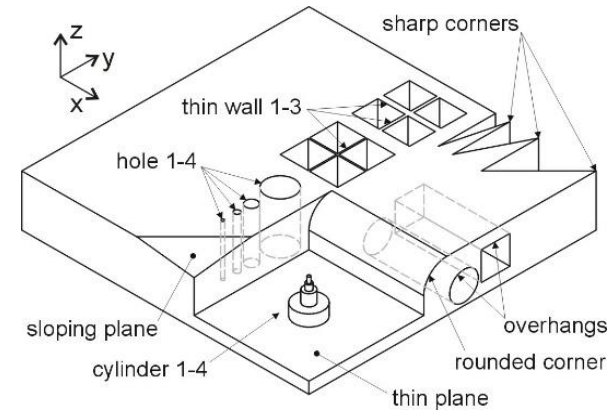

Figure 1. Test artifact used by Kruth [8].

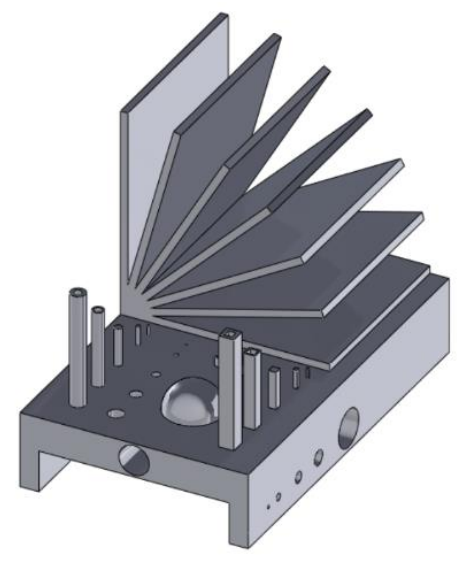

Figure 2. Test artifact used by Castillo [9].

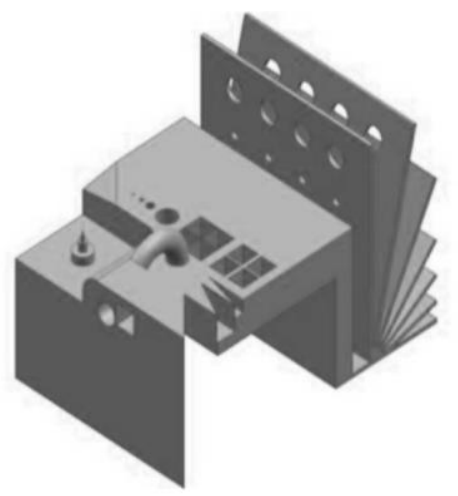

Figure 3. Test artifact used by Yasa [12].

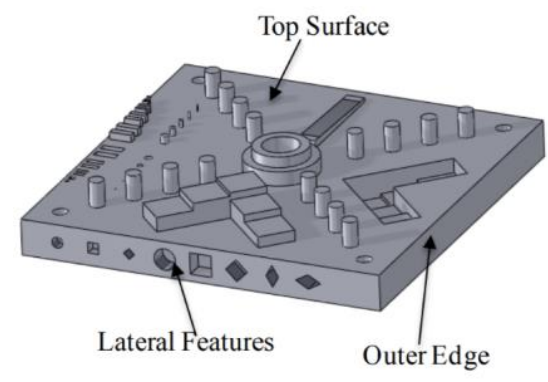

Figure 4. Test artifact proposed by Moylan [2].
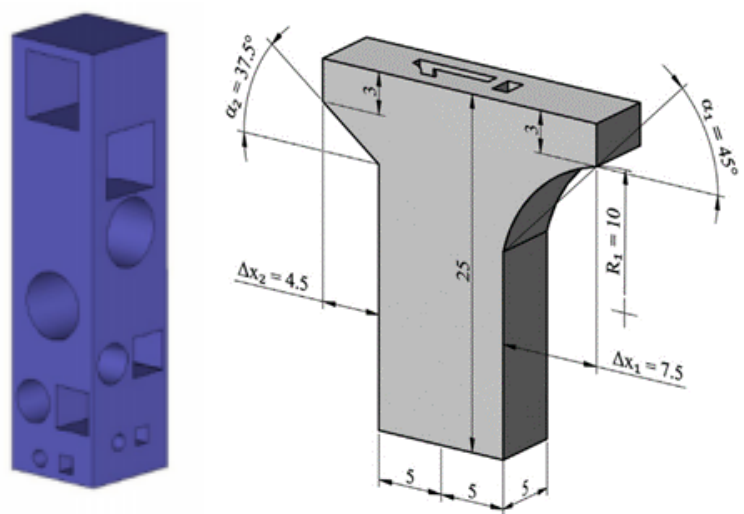

Figure 5. Overhanging test specimen used by Chen (left, [11]) and Atzeni (right, [12]).

There have also been many test specimens developed for the investigation of specific print properties, notably surface roughness and dross formation on unsupported overhanging features; these specimens can be seen in Fig. 5 [11, 12].

\section{B. Motivation for an Original Test Specimen}

An innovative test artifact is required for this work for the benchmarking of two DMLS machines being used in an ongoing research project, the EOS M290 (build volume of 250 x $250 \times 325 \mathrm{~mm}$ ) and EOS M100 printers (build volume of $\varnothing 100 \times 95 \mathrm{~mm}$ ), both produced by EOS GmbH. This work aims to compare builds on the two printers to identify variations in build quality between the machines, as well as the impact of specific orientations of features, including build direction and orientation to build platforms. Several specific requirements not addressed previously drive the need for a novel test artifact. First, this benchmarking requires the evaluation of as-built mechanical properties, so features must be designed and located in such a way as to require minimal post-processing, including cutting or machining, before conducting tensile and hardness tests. The new test specimen was also developed to include a measure of the impact of thermal gradients on the builds. Finally, it was adapted for the geometry of the M100 build volume, which would not be possible through simple scaling of previously developed artifacts. 


\section{Methodology}

The model for the newly presented test artifact is shown in Fig. 6 and Fig. 7. The artifact is generally a modified version of the artifact proposed by Moylan [2]. Overall dimensions for the build are $70 \mathrm{~mm} \times 70 \mathrm{~mm}$ to reach the outer regions of the M100 build envelope. Prints of the artifact are printed in a diamond with respect to the $\mathrm{x}$-axis of the machine to mitigate issues with sudden cross-sectional area increases for the recoating blade. All builds on the M290 and M100 printers were run using the EOS recommended default material settings, which have energy densities of $115 \mathrm{~J} / \mathrm{mm}^{\wedge} 3$ and $92 \mathrm{~J} / \mathrm{mm}^{\wedge} 3$, respectively. The material used was EOS StainlessSteel 316L.

The design includes small vertical (2) and lateral (6) features, steps for z-axis measurements (7), straight surfaces of various orientations (3), a ramp for analyzing the stair effect (13), and tower features for testing the printable aspect ratio (12) for which the general rule has been cited as 7:1 [13]. The artifact also includes unsupported circular (1), angled (5), and bridge-type overhangs (11). The bridge-type overhangs serve as a means of examining the increasing severity of the effects of overheating, which can be attributed to the poor conductivity of the supporting powder [4].

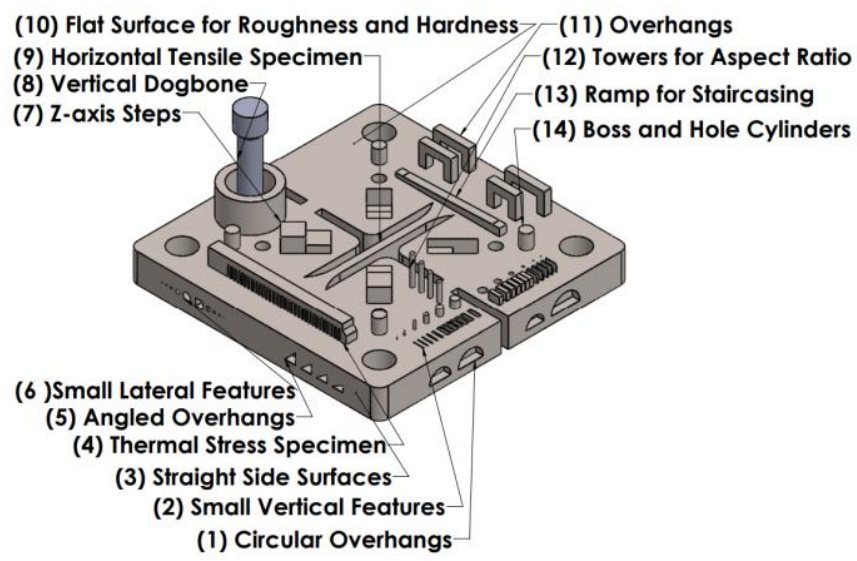

Figure 6. New test specimen design with feature labels.

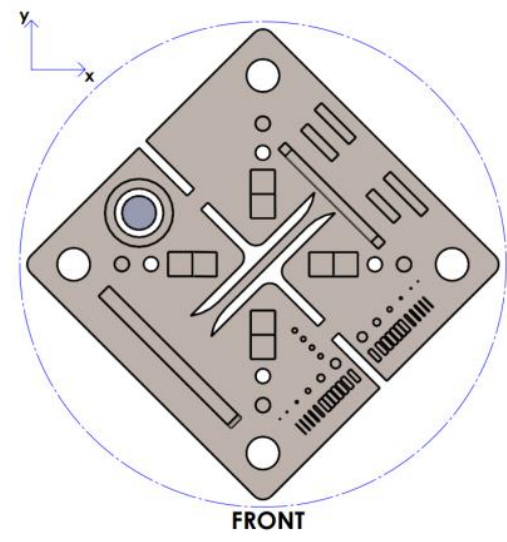

Figure 7. Top view drawing of the test artifact within the build platform area, with the $\mathrm{x}$-axis denoting the direction of the recoating blade.
TABLE I. TABLE OF TEST ARTIFACt FEATURE TYPES, DimENSIONS, AND CORRESPONDING CHARACTERIZATION TOOLS

\begin{tabular}{|c|c|c|c|}
\hline $\begin{array}{c}\text { Feature } \\
\text { No. }\end{array}$ & $\begin{array}{l}\text { Type of } \\
\text { Feature }\end{array}$ & Dimensions & Inspection Method \\
\hline 1 & $\begin{array}{c}\text { Circular } \\
\text { overhangs }\end{array}$ & $\begin{array}{l}5-8 \mathrm{~mm} \\
\text { diameter }\end{array}$ & ISM Digital Analyzer \\
\hline 2 & $\begin{array}{l}\text { Small vertical } \\
\text { features }\end{array}$ & $0.1-2 \mathrm{~mm}$ & ISM Digital Analyzer \\
\hline 3 & $\begin{array}{l}\text { Straight side } \\
\text { surfaces }\end{array}$ & $70 \mathrm{~mm}$ & Calipers, indicator \\
\hline 4 & $\begin{array}{c}\text { Thermal stress } \\
\text { specimen }\end{array}$ & $\begin{array}{l}38.5 \mathrm{~mm} \\
\text { length }\end{array}$ & Height gauge \\
\hline 5 & $\begin{array}{l}\text { Angled } \\
\text { overhangs }\end{array}$ & $\begin{array}{l}30-45 \\
\text { degrees }\end{array}$ & ISM Digital Analyzer \\
\hline 6 & $\begin{array}{l}\text { Small lateral } \\
\text { features }\end{array}$ & $0.1-2 \mathrm{~mm}$ & ISM Digital Analyzer \\
\hline 7 & Z-axis steps & $2 \mathrm{~mm}$ & Height gauge \\
\hline 8 & $\begin{array}{l}\text { Vertical dog } \\
\text { bone }\end{array}$ & $\begin{array}{c}5 \mathrm{~mm} \\
\text { diameter }\end{array}$ & $\begin{array}{l}\text { TQ SM1002 Bench Top } \\
\text { Tensile Testing Machine }\end{array}$ \\
\hline 9 & $\begin{array}{l}\text { Horizontal } \\
\text { tensile } \\
\text { specimen }\end{array}$ & $\begin{array}{c}2 \mathrm{~mm} \times 8 \\
\mathrm{~mm}\end{array}$ & $\begin{array}{l}\text { TQ SM1002 Bench Top } \\
\text { Tensile Testing Machine }\end{array}$ \\
\hline 10 & $\begin{array}{l}\text { Flat surface } \\
\text { for roughness } \\
\text { and hardness }\end{array}$ & $\mathrm{n} / \mathrm{a}$ & $\begin{array}{c}\text { Starett SR100 Surface } \\
\text { Roughness Tester, TQ } \\
\text { SM1002 Bench Top Tensile } \\
\text { Testing Machine, and ISM } \\
\text { Digital Analyzer }\end{array}$ \\
\hline 11 & Overhangs & $4-7 \mathrm{~mm}$ & ISM Digital Analyzer \\
\hline 12 & $\begin{array}{l}\text { Towers for } \\
\text { aspect ratio }\end{array}$ & $\begin{array}{l}5-8 \mathrm{~mm} \\
\text { length, } \\
1 \mathrm{~mm} \\
\text { diameter }\end{array}$ & ISM Digital Analyzer \\
\hline 13 & $\begin{array}{l}\text { Ramp for } \\
\text { staircasing }\end{array}$ & $\begin{array}{l}1 \mathrm{~mm} \text { rise, } \\
25 \mathrm{~mm} \text { run }\end{array}$ & $\begin{array}{l}\text { Starett SR100 Surface } \\
\text { Roughness Tester }\end{array}$ \\
\hline 14 & $\begin{array}{l}\text { Boss and hole } \\
\text { cylinders }\end{array}$ & $\begin{array}{c}3 \mathrm{~mm} \\
\text { diameter }\end{array}$ & Calipers \\
\hline
\end{tabular}

Other notable features and analysis techniques for the design are elaborated on in the following sections and are also summarized in Table 1 along with all other features. Inspection methods for all features have also been determined and are included in Table 1.

\section{A. Residual Stress}

Residual stresses are a known issue in powder bed fusion manufacturing techniques. The layer-wise production of the part results in large localized temperature fluctuations in a short period of time, resulting in thermal and residual stresses that can cause deformation in printed parts [14]. In the current specimen, a cantilever beam $38.5 \mathrm{~mm}$ in length is included to assess the magnitude of residual stresses created during manufacturing. This is based on a technique applied by Buchbinder [15] to study the extent preheating the base plate has on residual stresses and distortion. This has been adopted as a standard process by multiple researchers [16, 17, 18], including by $\mathrm{Li}$ et al. [16] to simulate heat flux and residual stress fields of selective laser melting prints.

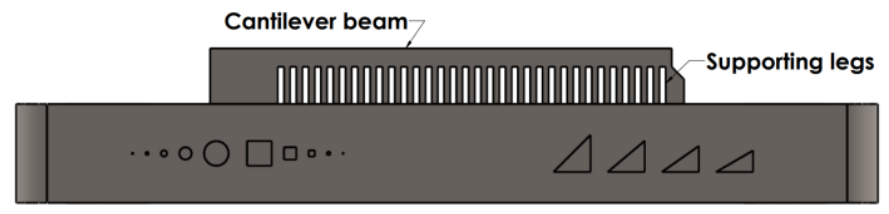

Figure 8. Side view of residual stress specimen. 
The inclusion of this feature on the test artifact (4), shown in Fig. 8, allows for a relative measure of residual thermal microstresses in the part by measuring the percent deflection at the tip of the feature after an incision is made to remove the supporting legs of the cantilever piece. When the supporting layers holding the beam are removed, the stresses become uneven, and the unstable beam deflects [19]. Measurements are taken while the test artifact is still on the base plate.

\section{B. Surface Properties}

Designated areas are defined on both the top and side surfaces of the test specimen for Brinell hardness testing. The top surface area used is noted in Fig. 6 and allows for three indents to be made with sufficient spacing ( 3 x diameter) and no interference of the artifact bosses with the indenter used. The side indents were made on either side of the circular overhangs. Brinell Hardness Number (BHN) values from the top surface of the build ( $\mathrm{x}-\mathrm{y}$ plane) were taken and compared with $\mathrm{BHN}$ values from the side surfaces (z-planes) to consider the effect that sintering and porosity upon solidification have on directionality; that is, whether hardness is an anisotropic property in the DMLS process [20]. A series of three BHN measurements were taken and averaged from each surface region. Using a TQ SM1002 Bench Top Tensile Testing Machine and digital calipers, the diameter of the indentation resulting from a $20 \mathrm{kN}$ maximum load from a $10-\mathrm{mm}$ steel indenter is measured.

Similarly, surface roughness, or texture morphology, resulting from the thermal effects of sintering is characterized. The test artifact included multiple areas on both the top surface and the sides for Ra roughness measurements to be taken, using a Starett SR100 Surface Roughness Tester. A series of 3 measurements are taken and averaged for the top ( $\mathrm{x}-\mathrm{y}$ plane) and side ( $\mathrm{z}$ plane) surfaces. Inhomogeneity in surface roughness would suggest that the heat transfer and cooling rate from sintering are different in the $\mathrm{x}-\mathrm{y}$, and $\mathrm{z}$ planes, and indicate that a post-processing polish may be required to mitigate chemical reactivity on the surface with higher roughness, more texture, and a duller finish.

\section{Tensile Strength}

The test artifact includes two specimens for tensile strength testing. One of the specimens is printed vertically and the other horizontally. This difference in build direction is important to test as it has been shown that build direction of parts printed through DMLS processes impacts their strength properties greatly [21]. The specimens will identify how these variations may be different between machines. The first specimen is a round dog bone $(5 \mathrm{~mm}$ diameter) in the $\mathrm{z}$-axis designed to be tested on a TQ SM1002 Bench Top Tensile Testing Machine. The second specimen is a plate-type dog bone, which is part of the test artifact base itself in the $x-y$ plane; the nominal dimensions of this tensile specimen are $2 \mathrm{~mm} \times 8 \mathrm{~mm}$ with $10 \mathrm{~mm}$ corner radii. The horizontal specimen was designed as part of the main body of the test artifact part for spatial efficiency, and it also allows for direct measurement of the test artifact strength as it will conduct thermal energy through the artifact. This tensile testing requires a custom gripper to ensure axial loading of the applied force. Both specimens are tested as built to simulate the mechanical behaviour of a part printed with minimal postprocessing, so to include any effects from the surface quality.

\section{ANALYSIS AND DISCUSSION}

A combined total of six test artifact parts were printed successfully in $316 \mathrm{~L}$ on the two printers, allowing for initial testing and some preliminary conclusions to be drawn. Four of the parts were printed on the M290 in two different orientations, 180 degrees from each other. These were fabricated simultaneously on the same build platform. The remaining two parts were printed on the M100 separately, also differing by 180 degrees.

It is worth noting that test prints led to changes to the initial artifact design, resulting in the final design shown in Fig. 5. The $\mathrm{z}$-axis dog bone was adjusted and shortened as insufficient feeding of the powder near build heights of $50 \mathrm{~mm}$ was identified as an issue on the M100. An additional cone volume support pattern was developed for the outer edges of the part to prevent the corners from lifting due to thermal stresses. Connecting volumes were added to the middle gap of the artifact for support when removing the part from the base plate; these volumes are cut before tensile testing.

The observed geometric deviations for M100 prints were -0.13 to $0.09 \mathrm{~mm}$ for features on the $\mathrm{x}-\mathrm{y}$ plane and -0.35 to $0.04 \mathrm{~mm}$ for features on lateral surfaces. On the M290, the $\mathrm{x}-\mathrm{y}$ and lateral geometric deviations were -0.15 to $0.15 \mathrm{~mm}$ and -0.45 to $0.02 \mathrm{~mm}$, respectively. The surface roughness of the M100 parts averaged Ra values of $10.6 \mu \mathrm{m}$ for the top and $9.5 \mu \mathrm{m}$ for the sides. For the M100, the Ra values were $12.7 \mu \mathrm{m}$ for the top and $10.2 \mu \mathrm{m}$ for the sides. All roughness measurements fell within the stated range in EOS documentation [22]. The relative residual stress data shows similar deflections of $36.4 \%$ and $37.3 \%$ for the M100 and M290 printers, respectively. Future work will include additional prints to further verify repeatability of the results, as well as a more in-depth analysis of geometric, mechanical, and overall build quality observations. However, it should be noted that both printers to date have shown good repeatability for previously printed parts.

\section{A. Comparison of Mechanical Properties}

Initial results from tensile testing show that the ultimate strengths for both the $\mathrm{z}$ and $\mathrm{x}-\mathrm{y}$ axes are similar for both machines. The strength results are also within the published results by EOS for machined parts. In terms of hardness, the results are displaying a clear indication of anisotropy, where the indentations made parallel to the build direction have larger BHN than the indentations perpendicular to the build direction. It has also been observed that the hardness values for artifacts built using the M290 are lower than those built using the M100.

\section{B. Comparison of EOS M100 and M290 Build Quality}

Observations from the current set of prints suggest that the resolution capabilities of the printers in the $x-y$ plane varies depending on whether the part is a boss or a hole, with the 
M100 more capable for the creation of small hole features, while the M290 is more capable in the creation of small bosses (Fig. 9). Table 2 categorizes small feature success based on observation with a digital microscope. A feature is considered to be failed $(\mathrm{F})$ if there is no formation for the bosses and if there are no open gaps for the holes, partial $(\mathrm{P})$ if there is an incomplete formation for the bosses and if the hole is mostly closed off for holes, and otherwise is considered to have successfully printed (S). Fig. 10 provides a labelled CAD visual of the small vertical features.

For lateral features, the M100 prints accumulated less dross formation and were thus more accurate. This observation would agree with assertions made by Chen [11] of dross formation decreasing with decreasing energy density. The same observation cannot yet be made for the bridge features. However, it is notable that for the M100, results from printing at orientations separated by 180 degrees suggest the dross formation is increased when the bridges are located in the back section of the build platform versus the front. Interestingly, the circular overhanging features, as well as the bottom edge of M100 prints, show clear effects of thermal degradation (Fig. 11), which indicates that there is more to investigate regarding the thermal gradient behaviour for these prints.

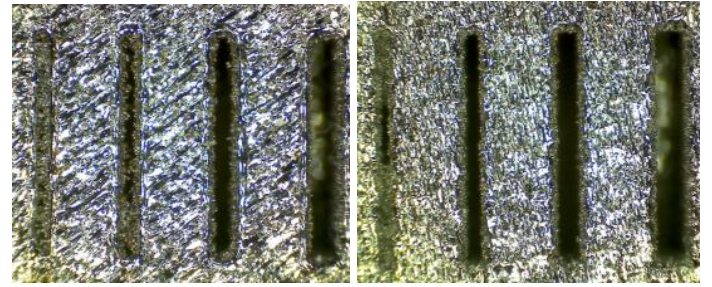

Figure 9. Success of small rectangular holes for M290_1 (left) and M100_1 (right) taken with ISM Digital Analyzer.

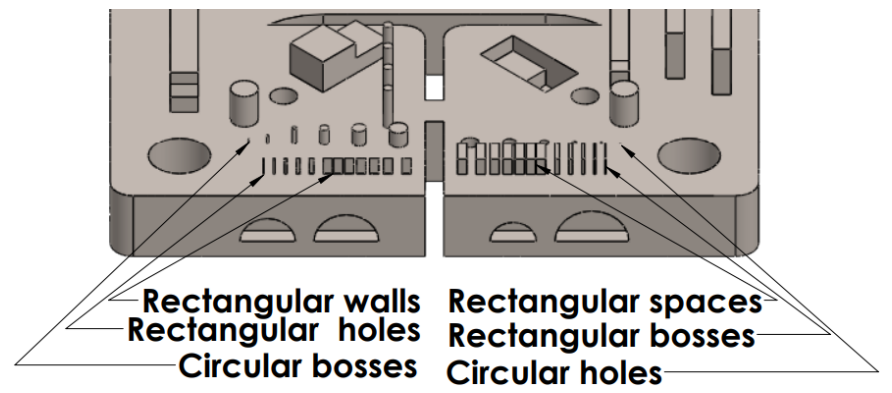

Figure 10. Small vertical features of test artifact.

TABLE II. TABle of Small Feature PRint Success

\begin{tabular}{|c|c|c|c|c|c|c|}
\hline \multirow{2}{*}{ Feature (100 $\boldsymbol{\mu m})$} & \multicolumn{2}{|c|}{ M100 } & \multicolumn{5}{|c|}{ M290 } \\
\cline { 2 - 7 } & $\mathbf{I}$ & $\mathbf{2}$ & $\mathbf{1}$ & $\mathbf{2}$ & $\mathbf{3}$ & $\mathbf{4}$ \\
\hline Rectangular boss & $\mathrm{F}^{\mathrm{a}}$ & $\mathrm{F}$ & $\mathrm{P}^{\mathrm{b}}$ & $\mathrm{F}$ & $\mathrm{F}$ & $\mathrm{F}$ \\
\hline Rectangular walls & $\mathrm{F}$ & $\mathrm{F}$ & $\mathrm{P}$ & $\mathrm{S}^{\mathrm{c}}$ & $\mathrm{S}$ & $\mathrm{F}$ \\
\hline Rectangular hole & $\mathrm{P}$ & $\mathrm{P}$ & $\mathrm{F}$ & $\mathrm{F}$ & $\mathrm{F}$ & $\mathrm{F}$ \\
\hline Rectangular spaces & $\mathrm{S}$ & $\mathrm{S}$ & $\mathrm{P}$ & $\mathrm{P}$ & $\mathrm{P}$ & $\mathrm{P}$ \\
\hline Circular boss & $\mathrm{F}$ & $\mathrm{F}$ & $\mathrm{S}$ & $\mathrm{S}$ & $\mathrm{S}$ & $\mathrm{S}$ \\
\hline Circular hole & $\mathrm{P}$ & $\mathrm{P}$ & $\mathrm{F}$ & $\mathrm{F}$ & $\mathrm{F}$ & $\mathrm{F}$ \\
\hline
\end{tabular}

a. Fail b. Partial c. Success

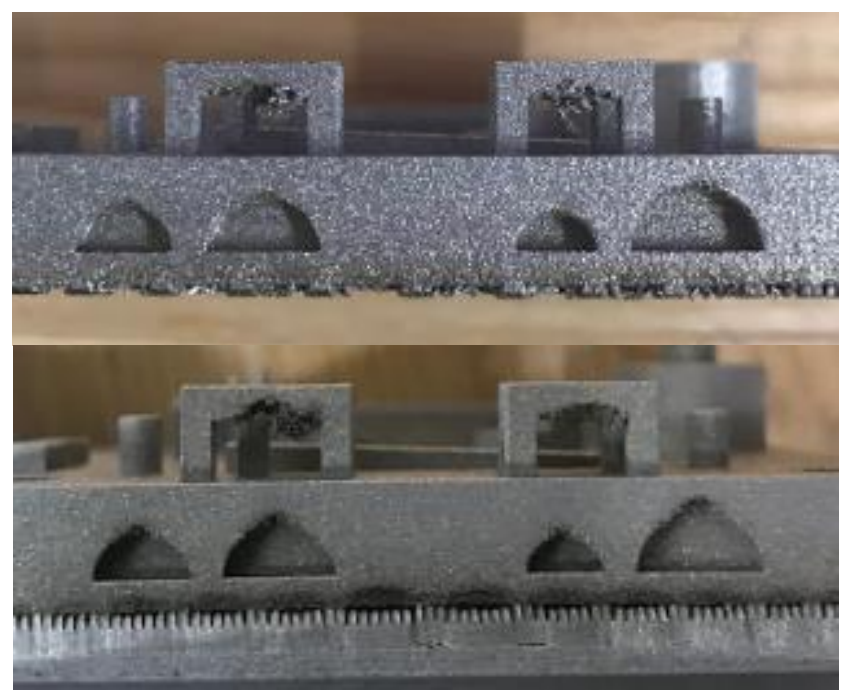

Figure 11. Sides of printed test artifacts showing dross formation on bridge overhangs for both M100 print (bottom) and M290 print (top) and overheating of the circular overhangs and bottom edge for the M100 print.

\section{Next Steps}

Early results from printing the test artifact show acceptable results for geometric accuracy, surface roughness, and mechanical properties and demonstrate the effect of anisotropy in the hardness and strength data. Dross formation indicates effects due to energy density and build volume location. Additional prints on both the M100 and M290 printers are to be completed to further validate these results and observations.

In this paper, we have presented a test artifact designed with the intent to perform initial investigations into multiple features simultaneously and identify results and trends requiring further study. Future work will involve the design of targeted test artifacts to conduct focused studies on these areas of interest. The design will allow for multiple instances of a specific feature, on one or multiple test specimens, to be printed in one build at varying locations and orientations to analyze the effect of these parameters.

Using Design of Experiments (DoE) methods, the exposure parameters of the printers (laser power, speed, and scan strategies) will also be varied to complete an array of builds and investigate the effect of printer parameters, as they have been shown to change the density and mechanical properties of printed parts [23, 24].

\section{CONCLUSION}

The design of a new test artifact required additions to allow for the measurement of as-built mechanical properties, deformation due to residual stress, and various geometric and surface qualities. Results recorded from initial 316L prints revealed values for surface roughness, hardness, and ultimate strength that varied depending on the axis of the measurement; all values were within the published ranges. Differences in the attainable resolution of the two DMLS printers for small features were also noted. Moving forward, further prints and a systematic investigation based on DoE will reveal the 
relationship between process parameters of the printers and selected mechanical properties of interest.

\section{REFERENCES}

[1] E. Yasa, F. Demir, G. Akbulut, N. Cizıoğlu, and S. Pilatin, "Benchmarking of different powder-bed metal fusion processes for machine selection in additive manufacturing," Proceedings of Solid Freeform Fabrication Symposium, Austin, Texas, USA, pp. 390-403, 2014.

[2] S. Moylan, J. Slotwinski, A. Cooke, K. Jurrens, and M. A. Donmez, "Proposal for a standardized test artifact for additive manufacturing machines and processes," Proceedings of the 2012 annual international solid freeform fabrication symposium, pp. 902-920, 2012.

[3] T. H. J. Vaneker, "The role of design for additive manufacturing in the successful economical introduction of AM," Procedia Cirp, vol. 60, pp. 181-186, 2017.

[4] Ö. Poyraz, E. Yasa, G. Akbulut, A.Orhangül, and S. Pilatin, "Investigation of support structures for direct metal laser sintering (DMLS) of IN625 parts," Proceedings of the Solid Freeform Fabrication Symposium, Austin, Texas, USA, pp. 560-574, 2015.

[5] W. S. Tan, S. R. Suwarno, J. An, C. K. Chua, A. G. Fane, T. H. Chong, "Comparison of solid, liquid and powder forms of 3D printing techniques in membrane spacer fabrication," Journal of Membrane Science, vol. 537, pp. 283-296, 2017.

[6] J. Richter and P. Jacobs, "Accuracy," Rapid Prototyping \& Manufacturing, pp. 287-315, 1992.

[7] D. Scaravetti, P. Dubois and R. Duchamp, "Qualification of rapid prototyping tools: proposition of a procedure and a test part," The International Journal of Advanced Manufacturing Technology, vol. 38, no. 7, pp. 683-690, 2008.

[8] J. P. V. Kruth, B. Vandenbroucke, J. Van Vaerenbergh, and P. Mercelis, "Benchmarking of different SLS/SLM processes as rapid manufacturing techniques," Proceedings of the Int. Conf. Polymers \& Moulds Innovations (PMI), 2005.

[9] L. Castillo, "Study about the rapid manufacturing of complex parts of stainless steel and titanium," TNO report with the collaboration of AIMME, 2005.

[10] M. K. Thompson, et al., "Design for additive manufacturing: trends, opportunities, considerations, and constraints," CIRP annals, vol. 65, no. 2, pp. 737-760, 2016.

[11] H. Chen, D. Gu, J. Xiong, and M. Xia, "Improving additive manufacturing processability of hard-to-process overhanging structure by selective laser melting," Journal of Materials Processing Technology, vol. 250, pp. 99-108, 2017.

[12] E. Atzeni and A. Salmi, "Study on unsupported overhangs of AlSi10Mg parts processed by Direct Metal Laser Sintering (DMLS), vol. 20, pp. 500-506, 2015.

[13] S. Moylan, J. A. Slotwinski, A. C. Cooke, K. Jurrens, and M. A. Donmez, "Lessons learned in establishing the NIST metal additive manufacturing laboratory," NIST Technical Note, 2013.

[14] J. Kruth, J. Deckers, E. Yasa and R. Wauthlé, "Assessing and comparing influencing factors of residual stresses in selective laser melting using a novel analysis method," Proceedings of the Institution of Mechanical Engineers, Part B: Journal of Engineering Manufacture, vol. 226, no. 6, pp. 980-991, Jun. 2012. doi: 10.1177/0954405412437085.

[15] D. Buchbinder, W. Meiners, N. Pirch, K. Wissenbach and J. Schrage, "Investigation on reducing distortion by preheating during manufacture of aluminum components using selective laser melting," Journal of Laser Applications, vol. 26, no. 1, Nov. 2013. doi: 10.2351/1.4828755.

[16] C. Li, J. F. Liu, X. Y. Fang and Y. B. Guo, "Efficient predictive model of part distortion and residual stress in selective laser melting," Additive Manufacturing, vol. 17, pp. 157-168, 2017. doi: 10.1016/j.addma.2017.08.014.

[17] I. Yadroitsava and I. Yadroitsev, "Residual stress in metal specimens produced by direct metal laser sintering," in 26th Annual International Solid Freeform Fabrication (SFF) Symposium, pp. 614-625, 2015.

[18] S. Tripathy, C. Chin, T. London, U. Ankalkhope and V. Oancea, "Process modeling and validation of powder bed metal additive manufacturing," in NAFEMS World Congress 2017.

[19] F. A. Kandil, J. D. Lord, A. T. Fry and P. V. Grant, "A review of residual stress measurement methods," NPL Materials Centre, Teddington, Middlesex, UK, 2001.

[20] C. Klahn, B. Leutenecker, and M. Meboldt, "Design strategies for the process of additive manufacturing," Procedia CIRP, vol. 36, pp. 230235, 2015.

[21] E. Koc, M. Coskun, and Z. C. Oter, "Anisotropic Mechanical Behaviour of direct metal laser sintering (DMLS) parts," unpublished.

[22] Electro Optical Systems, "EOS StainlessSteel 316L," (EOS art.-no. 9011-0032) datasheet, 2014.

[23] A. Simchi, "Direct laser sintering of metal powders: Mechanism, kinetics and microstructural features," Materials Science and Engineering: A, vol. 428, no. 1-2, pp. 148-158, 2016.

[24] W. Wang and S. Kelly, "A metallurgical evaluation of the powder-bed laser additive manufactured 4140 steel material," JOM, vol. 68 , no. 3, pp. 869-875, 2016. 